\title{
Spotlight turns on cosmetics for Asian skin
}

Ichiko Fuyuno, Tokyo

Cosmetics companies and scientists around the globe are expanding their efforts to understand Asian skin problems, a symposium was told earlier this month.

Many skin treatments have been developed for Caucasian women, but women in east Asia have different skin problems, say specialists. These include dark melanin spots, which result mainly from exposure to the Sun's ultraviolet rays.

On 11 December, 16 researchers from France and several Asian countries addressed a symposium in Paris organized by Moët Hennessy Louis Vuitton (LVMH), a Paris-based company specializing in luxury brands, including cosmetics. The researchers described their latest findings on skin ageing, the skin's reaction to stress, and those melanin spots.

"In the past, researchers just tried to get rid of spots that appeared on the skin," says Hachiro Tagami, a dermatologist at Japan's Tohoku University in Sendai. "But now they are trying to find out why spots develop."

In general, researchers say, dark spots appear when the activity of melanocytes is disrupted, usually by excessive exposure to ultraviolet light. Melanocytes are cells that produce the pigment melanin, and their activity levels help to determine the skin's condition, as well as its colour.

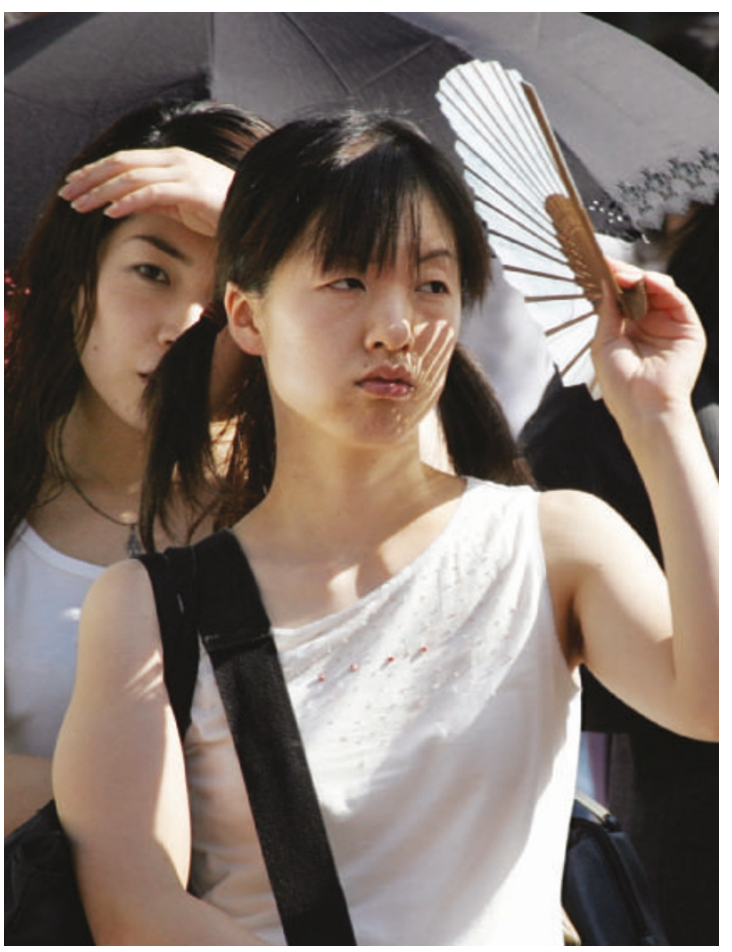

Beauty spots: the skin of Asian and Caucasian women differs in its sensitivity to the Sun's ultraviolet rays.

Asian women find that melanin pigments develop in their facial skin at earlier ages than they occur in Caucasian women, say researchers, and that the activity of their melanocytes seems to be more sensitive to stress. But Asian skin retains more of its tension and is less likely to wrinkle.
Researchers are now gaining insight into the genetic and biochemical differences that might explain these contrasts.

In a collaboration with Bordeaux University, for example, workers at $\mathrm{LVMH}$ have come up with new data in the search to explain melanin spot formation. Beneath such spots, the melanocytes, which are usually found in the epidermis, seem to sink into the dermis by disrupting the thin structure between the layers known as the dermo-epidermal junction (M. CarioAndre et al. J. Cutan. Pathol. 31, 441-447; 2004).

LVMH says it is developing these findings to launch a skincare range for east Asia under its Christian Dior brand. Meanwhile, cosmetics researchers at Procter \& Gamble claim to have found a method of controlling the transfer of melanin from melanocytes, using a substance called niacinamide. (T. Hakozaki et al. Br. J. Dermatol. 147, 20-31;2002).

Regulators will be keeping a close eye on the safety of these skin treatments, however. Last year, Japan's health ministry ordered 12 Japanese and foreign cosmetics companies to stop selling products containing kojic acid, which is believed to reduce melanin levels in the skin. The agent's cosmetic use was approved in 1988 , but animal tests have raised fears that it may cause cancer.

\section{Nano names go on Internet sale in hope of mega profit}

\section{Jim Giles}

For sale: hundreds of Internet domain names, all starting with 'nano'. Vendor prefers to sell collection as a single unit would suit large funding organization.

This curious offer is being made by Steve Sobol, a US environmental consultant and Internet entrepreneur. Over the past two years, Sobol's company ESH Sciences has snapped up more than $\mathbf{9 0 0}$ domain names in the hope of selling the collection to an organization such as the US National Science Foundation (NSF).

Trading in domain names can be big business. Speculators can register names for as little as US\$7 a year and, if they choose well, resell for a considerable profit. One of this year's biggest transactions involved the domain name creditcards.com, which sold for $\$ 2.75$ million. Such returns entice entrepreneurs to bag large numbers of names in the hope that one will turn out to be hot online property.

“Domains with 'nano' in them haven't appeared in our charts of most costly names," says Ron Jackson, editor of Domain Names Journal, an online magazine. "But nanotechnology has huge potential. That's why it's worth locking up the domains for future use."

Sobol, who describes the venture as providing a "very good public service" with "some greed in there too", declines to say how much his collection is on sale for. But he points out that nanorobotics.com is currently available from another source for $\$ 470$, and says that nanocolor.com sold earlier this year for $\$ 3,300$.

So far, Sobol has not had any offers for his collection. He says he contacted the NSF in June 2003 about the names but received no reply. When he tried to attract attention to his venture by advertising it on an online science-discussion group, he received only one reply: he was accused of 'cyber-squatting' - a derogatory term for the practice of buying up domain names that should be owned by somebody else.

A partial list of Sobol's domains, available on his website naknow.com, includes such oddities as 'nanosociology' and 'nanocrimelab'. He also holds at least one name that corresponds to an actual research project: 'Nanocmos' is a collaboration into semiconductor research funded by the European Union. Project leaders could choose to take Sobol to task over the name, and apply to a tribunal to ask that the site be handed over at cost. But it is unclear whether such a move would be successful - or worth the effort.

For more news and analysis go to news@nature.com www.nature.com/news 